\title{
Development of Glimepiride Solid Dispersion using the Coprocessed Excipients of Polyvinylpyrrolidone, Maltodextrin, and Polyethylene Glycol
}

\author{
Silvia Surini ${ }^{*}$, Claudia Nelrima Evangelista, Raditya Iswandana \\ Laboratory of Pharmaceutics and Pharmaceutical Technology Development, Faculty of Pharmacy, Universitas Indonesia, Depok, INDONESIA.
}

\begin{abstract}
Objectives: The aim of this work was to produce the solid dispersion of glimepiride (GMP-SD) based on the coprocessed excipient of polyvinylpyrrolidon (PVP), maltodextrin (MD) and polyethylene glycol (PEG). Methods: The PVP-MD-PEG coprocessed excipients were prepared in the ratio of $1: 1: 1,1: 1: 2,1: 2: 1,2: 1: 1,2: 2: 1,2: 1: 2$, and 1:2:2; as well as characterized. Furthermore, GMP-SD was prepared by spray drying with a ratio of $1: 2$ for glimepiride and the excipients. The obtained GMP-SD were characterized by fourier transform infrared spectroscopy (FTIR), differential scanning calorimetry (DSC), X-ray diffraction, and scanning electron microscopy. Dissolution study of GMP-SD was carried out in a phosphate buffer $\mathrm{pH} 7.4$ at $\pm 37^{\circ} \mathrm{C}$ for $120 \mathrm{~min}$. Results: The PVP-MD-PEG coprocessed excipients displayed irregular shapes and rough and distributed in a wide range of particle sizes with mostly under $125 \mu \mathrm{m}$. The coprocessed excipients exhibited the moisture content of $5-8 \%, \mathrm{pH}$ of $5-8$, and the flow rate of 2.5-4.0 gr/s. The results revealed that there was no chemically interaction between GMP and the coprocessed excipients. Thermal analysis demonstrated that the crystal phase reduction was occurred, thus it was
\end{abstract}

transfomed to amorph form. The dissolution study revealed that GMP-DP proved the dissolution enhancement of GMP compared to the pure GMP. Conclusion: GMP-SD with the PVP-MD-PEG coprocessed excipients has benefit to enhance dissolution rate of glimepiride.

Key words: Coprocessed excipient, Glimepiride, Maltodextrin, Polyethylene glycol, Polyvinylpyrrolidone, Solid dispersion.

\section{Correspondence}

Silvia Surini, Laboratory of Pharmaceutics and Pharmaceutical Technology Development, Faculty of Pharmacy, Universitas Indonesia, Depok 16424, INDONESIA.

Phone: +62-21-7270031

Email: silvia@farmasi.ui.ac.id, icapps2017.farmasiui@gmail.com

DOI: 10.5530/jyp.2018.2s.9

\section{INTRODUCTION}

Coprocessed excipient is a combination of two or more excipients that have a better visual advantage that cannot be achieved by using the common physical mixing with the same excipient. ${ }^{1}$ Coprocessed excipient is prepared by a specific technique using drum-drying and spray drying process. $^{2}$ Coprocessed excipients can be modified physically without changing their chemical structure. ${ }^{3}$ The combination of selected excipients can complement each other to cover the undesirable properties of each excipient while simultaneously maintaining or increasing the desired properties. $^{2}$

Oral administration route is one of the most widely used routes today. Drugs with oral administration can not directly enter the circulation system and must undergo pharmaceutical processes before they can be absorbed. ${ }^{4}$ Active compounds formulated in oral dosage forms must be released from the excipient to dissolve then diffuse and transferred between membranes which will eventually absorbed to produce therapeutic response. ${ }^{5}$ However, most of the drugs belong to Biopharmaceutical Classification System (BCS) class II which means drugs with low solubility and high permeability. Drugs with low solubility in water often have a low dissolution profile that affects oral dosage form bioavalibility and their absorption. The bioavailibility will determine the effication, intensity, and drug therapeutic response duration. ${ }^{6}$

The rate of drug dissolving in the body can accelerate absorption process to produce therapeutic effects in patients, but not all drugs are soluble in water. ${ }^{7}$ Modification can be done to increase drug solubility in water, i.e solid dispersion. Solid dispersion is a dispersion of one or more active compounds in an inert carrier or matrix in solid state. Solid dispersion can be prepared using melting, solvent, and melting-solvent method. ${ }^{8}$

Polyvinylpyrrolidone (PVP), maltodextrin (MD) and polyethylene glycol (PEG) are some of the excipients that are often used as carriers to increase dissolution rate in the form of solid dispersions. PVP is a hydrophilic polymer that can form an amorphous solid dispersion thereby increasing solubility and drug release. Maltodextrin is also a hydrophilic polymer with a high solubility in water and porous structure. Its circular structure creates a greater surface area resulting in a more efficient rehydration, thus a mixture of maltodextrin with other compound can increase solubility. ${ }^{9}$ PEG is very effective in aqueous environment and forms a two different phases of polymer systems. When PEG is attached to other polymer molecule, it can affect the chemical properties and solubility of drug molecule so that they can dissolve easily in bodily fluids. ${ }^{10}$

Glimepiride is one of the drugs that needs a dissolution rate enhancer. Glimepiride is a sulfonylurea antidiabetic third-generation oral medicine indicated for diabetes mellitus type 2 patients. Glimepiride is a BCS class II drug, ${ }^{11}$ which has a low solubility but high permeability. Physicochemical modification in surface properties, solubility, size, particle, polimorfism, molecule/atom/ion size and stability are needed to improve the absorption rate. ${ }^{6}$ Glimepiride is practically insoluble in water, slightly

This is an open access article distributed under the terms of the Creative Commons Attribution-NonCommercial-ShareAlike 4.0 License, which allows others to remix, tweak, and build upon the work non-commercially, as long as the author is credited and the new creations are licensed under the identical terms. 
soluble in methanol, ethanol, ethyl acetate and acetone also sparingly soluble in dichloromethane but soluble in dimethylformamide.

In this study, the coprocessed excipients of Polyvinylpyrrolidone (PVP), maltodextrin (MD) and polyethylene glycol (PEG) was prepared, then applied in production of the solid dispersion of glimepiride (GMP-SD) by spray drying method to increase the dissolution rate of glimepiride.

\section{MATERIALS AND METHODS}

\section{Materials}

Glimepiride (Kimia Farma, Indonesia), PEG 4000 (Duchefa Biochemie, Germany), PVP K-30 (Nanhang Industrial Co, LTD, China.), MD DE 18-20 (Zhucheng Dongxiao Biotechnology Co, LTD, China), dichloromethane (Merck, Germany), methanol (Merck, Germany), potassium dihydrogenphosphate (Merck, Germany), natrium hydroxide (Merck, Germany), aquadest (PT. Ikapharmindo Putramas, Indonesia).

\section{Preparation of the coprocessed excipients}

PVP K-30, MD DE 18-20, and PEG 4000 was dissolved in water with a ratio of $1: 1: 1,1: 1: 2,1: 2: 1,1: 2: 2,2: 1: 1,2: 1: 2$, and 2:2:1 until a homogenous solution was formed. The solution was dried using drum dryer until a dry powder mass was formed. The excipient concentration ratio was chosen randomly and determined in Table 1.

\section{Characterization of the coprocessed excipients Shape and morphology}

Scanning electrom microscope (SEM) was used to observe particle size and surface texture of PVP-MD-PEG powder. The powder was placed in a copper and coated with gold. ${ }^{3}$

\section{Organoleptic observation}

Excipient powder was evaluated for physical appearance, including color, and other physical properties.

\section{Particle size distribution}

One hundred miligrams of excipient sample was placed in sieve with mesh 120, 80, 60, 45, and 35 stacked from the highest size at the bottom and the smallest at the top. Shieving was set at $30 \mathrm{rpm}$ for $20 \mathrm{~min}$. The remaining powder in each shieve and container at the bottom was weighed and the weight percentage was calculated.

\section{Moisture content}

Moisture content analysis was done using moisture balance instrument that was heated for $10 \mathrm{~min}$ prior to use. Two grams of powder was placed on the alumunium container evenly and the temperature was set at $105^{\circ} \mathrm{C}$. The reading was then recorded.

\section{Flow rate}

Flow rate evaluation of PVP-MD-PEG powder was done by placing $10 \mathrm{~g}$ of powder in flowmeter funnel and the surface was evenly leveled without any pressure and the instrument was started. The time for all powder to flow through the funnel was used to calculate the flow rate that was expressed in $\mathrm{g} / \mathrm{sec}$.

Table 1: Composition of the coprocessed excipient.

\begin{tabular}{cccccccc}
\hline Composition & E1 & E2 & E3 & E4 & E5 & E6 & E7 \\
\hline PVP (g) & 166 & 125 & 125 & 100 & 250 & 200 & 200 \\
MD (g) & 166 & 125 & 250 & 200 & 125 & 100 & 200 \\
PEG (g) & 166 & 250 & 125 & 200 & 125 & 200 & 100 \\
\hline
\end{tabular}

\section{Preparatios of the glimepirid solid dispersion}

Glimepiride and coprocessed excipient were weighed with a ratio of 1:2. Glimepiride was dissolved in $400 \mathrm{ml}$ methanol and coprocessed excipient was dissolved in $100 \mathrm{ml}$ aquadest. Both solution was mixed and sprayed using spray dryer with a flow rate of $10 \mathrm{ml} / \mathrm{min}$. The inlet and outlet temperature were set to $100^{\circ} \mathrm{C}$ and $70^{\circ} \mathrm{C}$, respectively. The result was stored in dessicator at room temperature and characterized. ${ }^{12}$

\section{Glimepiride assay}

Glimepiride was weighted 2.4 miligrams and then dissolved in $50 \mathrm{ml}$ dichloromethane. Thes solution was sonicated for $15 \mathrm{~min}$ and filtered. Filtrate was analyzed using UV-Vis spectrophotometer at $230.4 \mathrm{~nm} .{ }^{12}$

\section{Evaluation and characterization of solid dispersion Fourier transform infrared spectroscopy (FT-IR)}

The analysis was conducted on solid dispersion of glimepiride-coprocessed excipient and its physical mixture using $\mathrm{KBr}$ tablet. One miligram of sample was dispersed in $100 \mathrm{mg} \mathrm{KBr}$ and pulverized until homogenous then placed into FT-IR disc. The analysis was done at wavelenght $450-4000 \mathrm{~cm}^{1}$. The spectrum was recorded in FT-IR at $4000-400 \mathrm{~cm}^{-1} .^{13}$

\section{Differential scanning calorimetry (DSC)}

Thermal analysis was conducted on glimepiride and solid dispersion using DSC. 5 to 10 miligrams sample was placed in a container and heated from $50-300^{\circ} \mathrm{C}$ with heating rate of $20^{\circ} \mathrm{C} / \mathrm{min}$. Endothermic or exothermic process can be observed in the thermogram. ${ }^{13}$

\section{X-ray diffraction}

$\mathrm{X}$-ray diffraction analysis was conducted on glimepiride and glimepiride-coprocessed excipients solid dispersion. The analysis was recorded at an interval of $5^{\circ}-80^{\circ} / 2 \theta$ using $\mathrm{x}$-ray radiation diffractometer $\mathrm{Cu} .{ }^{13}$

\section{Scanning electron microscopy (SEM)}

The morphology was analyzed using SEM to observe the shape and particle size. The sample was placed in a holder coated with conductive tape and coated with gold $\mathrm{Au})$ in a vacuum evaporator.

\section{Dissolution study}

Dissolution examination was done to glimepiride and glimepiridecoprocessed excipients solid dispersion using beaker glass and stirrer (100 rpm) for $120 \mathrm{~min}$. Phosphate buffer $\mathrm{pH} 7.4(250 \mathrm{ml})$ at $37^{\circ} \mathrm{C}$ was used as a medium. Four miligrams glimepiride and glimepiridecoprocessed excipients solid dispersion equal to $4 \mathrm{mg}$ glimepiride were weighed and added to dissolution medium. Ten mililiter sample was taken at 5, 10, 20, 30, 45, 60, 90, $120 \mathrm{~min}$. Each of the sample was added with $10 \mathrm{ml}$ medium with the same temperature and filtered. The filtrate was analyszed using UV-Vis spectrophotometer at $230.4 \mathrm{~nm} .{ }^{13}$

\section{RESULTS}

\section{Preparation of PVP-MD-PEG coprocessed excipient}

The preparation of coprocessed excipient was conducted by using drumdrying method. Process rendement result (Table 2) showed that all formulae had a varying value. Coprocessed excipient with the highest maltodextrin concentration showed the lowest percentage.

\section{Coprocessed excipient characterization Physical appearance}

Organoleptic evaluation showed coprocessed excipient was in the form of flakes or thin small plates after drum-drying process. Particle size reduction process using a blender was needed to obtain fine powders. 
Table 2: Properties of the PVP-MD-PEG coprocessed excipients.

\begin{tabular}{cccc}
\hline $\begin{array}{c}\text { Coprecess } \\
\text { excipients } \\
\text { PVP-MD-PEG }\end{array}$ & $\begin{array}{c}\text { Yield } \\
(\% \mathrm{w} / \mathrm{w})\end{array}$ & $\begin{array}{c}\text { Moisture } \\
\text { content } \\
(\% \mathrm{w} / \mathrm{w})\end{array}$ & $\begin{array}{c}\text { Flow rate } \\
(\mathrm{g} / \mathrm{sec})\end{array}$ \\
\hline $1: 1: 1$ & 76.0 & $6.10 \pm 0.03$ & $3.53 \pm 0.32$ \\
$1: 1: 2$ & 74.0 & $5.91 \pm 0.17$ & $3.26 \pm 0.11$ \\
$1: 2: 1$ & 68.0 & $8.02 \pm 0.02$ & $2.54 \pm 0.15$ \\
$1: 2: 2$ & 78.0 & $7.65 \pm 0.05$ & $3.99 \pm 0.21$ \\
$2: 1: 1$ & 84.4 & $4.96 \pm 0.23$ & $4.33 \pm 0.17$ \\
$2: 1: 2$ & 88.0 & $6.43 \pm 0.03$ & $3.22 \pm 0.39$ \\
$2: 2: 1$ & 77.4 & $6.54 \pm 0.06$ & $3.13 \pm 0.09$ \\
\hline
\end{tabular}

Table 3: The yield value and the glimepiride content of the glimepiride solid dispersion.

\begin{tabular}{ccc}
$\begin{array}{c}\text { Coprocessed excipient } \\
\text { PVP:MD:PEG }\end{array}$ & Yield value (\%) & $\begin{array}{c}\text { Content } \\
(\%)\end{array}$ \\
\hline $1: 1: 1$ & 80.00 & 75.50 \\
$1: 1: 2$ & 93.33 & 86.06 \\
$1: 2: 1$ & 90.00 & 74.75 \\
$1: 2: 2$ & 93.33 & 107.63 \\
$2: 1: 1$ & 73.33 & 84.09 \\
$2: 1: 2$ & 90.00 & 101.33 \\
$2: 2: 1$ & 83.33 & 100.18 \\
\hline
\end{tabular}

Table 4: Endothermic peak, melting enthalpy, and X-ray diffractogram height values of solid dispersions.

\begin{tabular}{cccc}
\hline Sample & $\begin{array}{c}\text { Endothermic } \\
\text { peak }\left({ }^{\circ} \mathrm{C}\right)\end{array}$ & $\begin{array}{c}\text { Melting } \\
\text { enthalpy }(\mathrm{J} / \mathrm{g})\end{array}$ & $\begin{array}{c}\text { Diffractogram } \\
\text { height }\end{array}$ \\
\hline GMP & 213.43 & 143.9287 & 11173.6 \\
DP 1:1:1 & 191.53 & 104.9004 & 2773.3 \\
DP 1:1:2 & 196.57 & 78.7598 & 5792.7 \\
DP 1:2:1 & 193.07 & 78.7598 & 4157.54 \\
DP 1:2:2 & 200.02 & 63.5221 & 5660.63 \\
DP 2:1:1 & 186.26 & 63.6556 & 4921.57 \\
DP 2:1:2 & 191.60 & 62.8997 & 5660.41 \\
DP 2:2:1 & 192.41 & 68.5999 & 4670.99 \\
\hline
\end{tabular}

Each of PEG, PVP dan Maltodextrin powders were white but after drum drying in high temperature, the powders became broken white. ${ }^{14}$

\section{Morphology}

Observation on morphology of the PVP-MD-PEG coprocessed excipients was performed using scanning electron microscope (SEM). Figure 1 shows that the PVP-MD-PEG coprocessed excipients possessed irregularshaped of flakes and rough surfaces.

\section{Particle size distribution}

Figure 2 showed that coprocessed excipient was distributed in a wide range of sizes with mostly under $<125 \mu \mathrm{m}$. Coprocessed excipient PVPMD-PEG 1:2:1 had 78\% particles under $<125 \mu \mathrm{m}$ which was the highest percentage while coprocessed excipient PVP-MD-PEG 2:1:2 had the lowest (38\%).

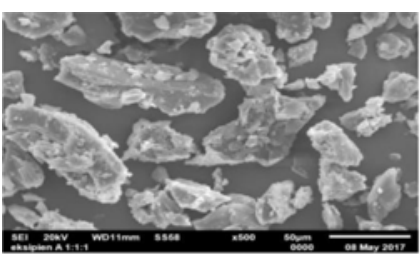

(a)

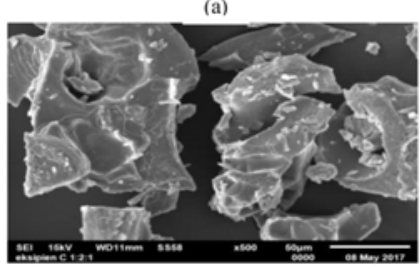

(c)

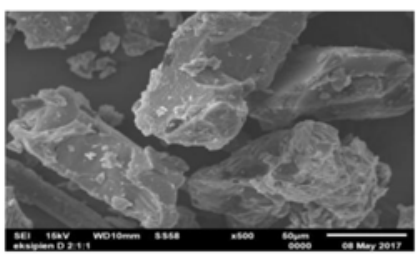

(e)

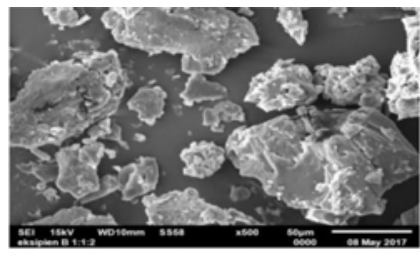

(b)

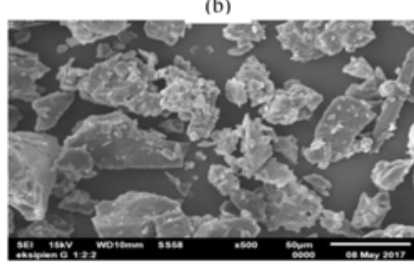

(d)

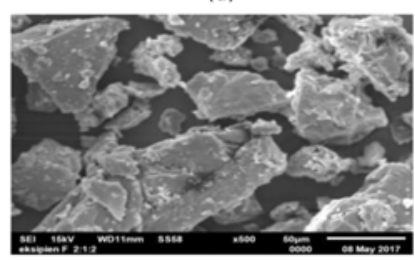

(f)

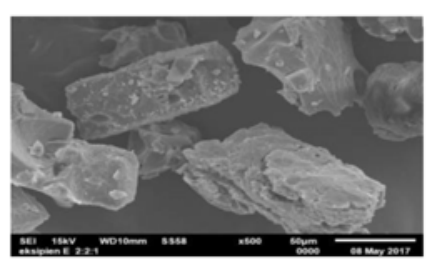

(g)

Figure 1: The SEM micrographs of the PVP-MD-PEG coprocessed excipients in the ratio of (a) 1:1:1, (b) 1:1:2, (c) 1:2:1, (d) 1:2:2, (e) 2:1:1, (f) 2:1:2, and (g) 2:2:1 with magnification of $500 x$.

\section{Moisture content}

As shown at Table 2, the coprocessed excipient 2:1:1 had the lowest moisture content and the coprocessed excipient 1:2:2 had the highest.

\section{Flow rate}

Table 2 showed that the coprocessed excipient 1:2:1 had the flow rate of $2.53 \mathrm{~g} / \mathrm{sec}$, while coprocessed excipient 2:1:1 had the highest flow rate of $4.33 \mathrm{~g} / \mathrm{sec}$. The flow rate of all the coprocessed excipient was under $10 \mathrm{~g} / \mathrm{sec}$, so the excipient powder revealed fair flow rate.

\section{Solid dispersion preparation}

Yield value of glimepiride solid dispersion is displayed in Table 3.

\section{Glimepiride content}

Glimepiride assay result (Table 3) would be used as a base for dissolution sample weight so the amount of glimepiride contained will be the same.

\section{Solid dispersion characterization}

\section{Physical appearance}

Solid dispersion drying process using spray dryer produced finer powders compared to coprocessed excipient powders using drum dryer. The powders were also smaller in size compared to pure glimepiride. ${ }^{15}$ 


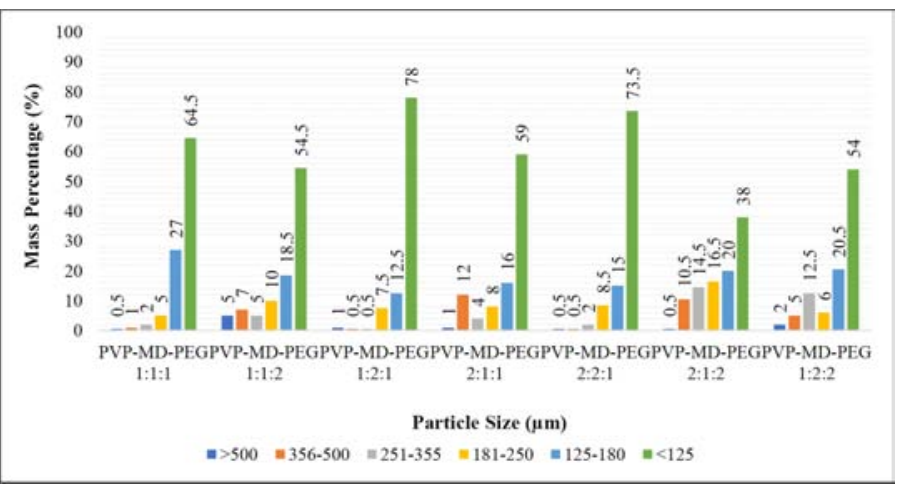

Figure 2: Particle size distribution of the coprocessed excipients.

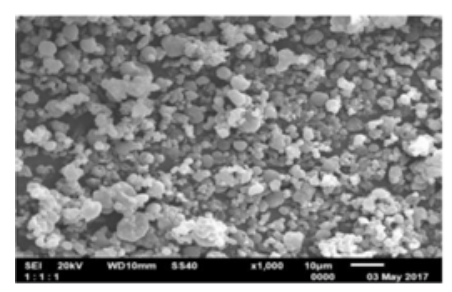

(a) 1

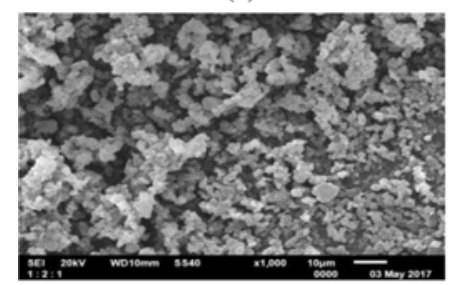

(c)

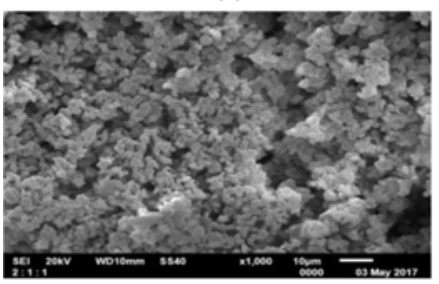

(e)

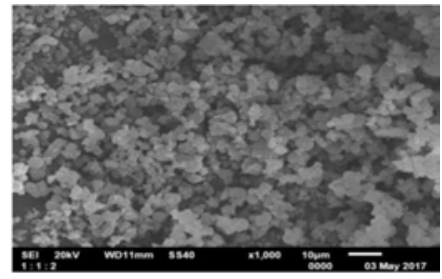

(b)

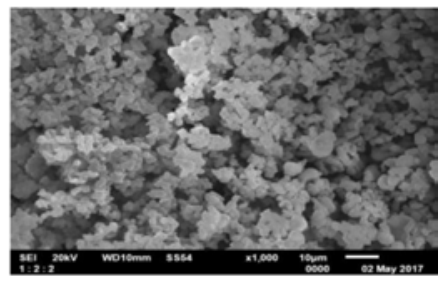

(d)

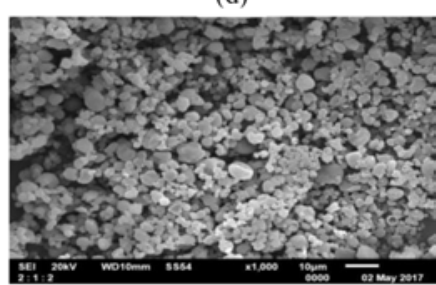

(f)

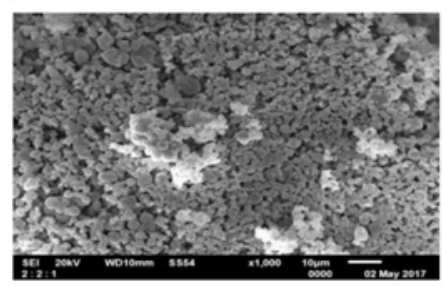

(g)

Figure 3: Solid dispersions morphology with magnification 1000x: (a): 1:1:1, (b): 1:1:2, (c): 1:2:1, (d): 1:2:2, (e): 2:1:1, (f): 2:1:2, (g): 2:2:1.

\section{Morphology}

Glimepiride was asymmetrical and different sizes. However, all solid dispersion formulation was spherical in form, showed in Figure 3.

\section{Fourier transform infrared spectroscopy (FT-IR)}

There was no difference in spectrum of physical mixture and solid dispersion, hence there were no chemical interaction during solid dispersion preparation.

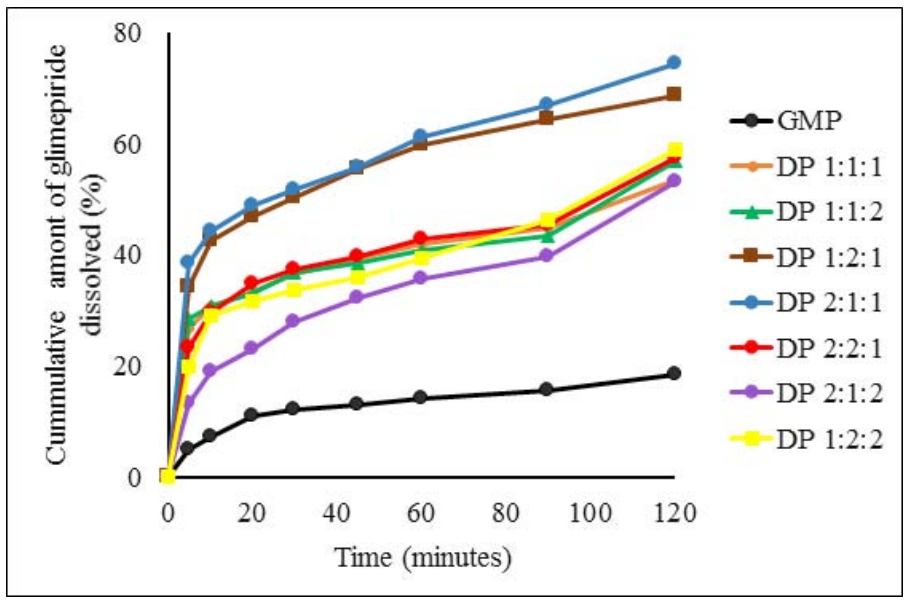

Figure 4: Dissolution profiles of the glimepiride solid dispersions.

\section{Differential scanning calorimetry (DSC)}

The significant change of pure glimepiride and glimepiride solid dispersion enthalpy showed the decrease of crystalline phase in solid dispersion so low energy was needed to melt the crystals present (Table 4).

\section{X-ray diffraction}

Solid dispersion characterization with $\mathrm{x}$-ray diffraction was done to see if there's any different in crystal form of glimepiride and solid dispersion. $\mathrm{X}$-ray diffraction results can be seen in Table 4 .

\section{Dissolution study}

Figure 4 shows the dissolution profiles of the GMP-SD with the PVPMD-PEG coprocessed excipients. In $5 \mathrm{~min}$, there was an increase of dissolution rate up to 7.59 -fold in solid dispersion with coprocessed excipient 2:1:1 compared to pure glimepiride. Pure glimepiride had only $5.06 \%$ of drugs released, while in solid dispersion 2:1:1 was $38.43 \%$. These results were also supported in the data at 120 min which showed only $18.45 \%$ of pure glimepiride were dissolved and solid dispersion 2:1:1 showed an increase up to 4.02-fold compared to pure glimepiride (74.22\%). Solid dispersion 2:1:2 showed the lowest increase of $2.87 \mathrm{x}$ with a percentage of $53.04 \%$ followed by coprocess $1: 1: 1,1: 1: 2,2: 2: 1,1: 2: 2$, and $1: 2: 1$ with values of $53.40 \%, 56.76 \%, 57.32 \%, 58.90 \%$, and $68.52 \%$, respectively.

\section{DISCUSSION}

In this study, PVP, MD and PEG were prepared by coprocessed method. Then the coprocessed excipient and glimepiride were melted together and dried using the spray-drying method. Coprocessed excipient with the highest maltodextrin concentration showed the lowest percentage. This might be due to the high concentration of maltodextrin resulting in a stickier mass so the possibility of the mass to stick in container and drum dryer instrument was higher. The physical appearance of the coprocessed excipient showed that there is a change of appearance after drum drying was caused by the method used to dry the coprocessed excipient is drum dryer. In the drum-drying process, pureed raw ingredients are dried at relatively low temperatures over rotating, high-capacity drums that produce sheets of drum-dried product. That's what makes the powder produced using drum dryer were not fine as using spray-dryer. The shape of PVP-MD-PEG coprocessed excipients possessed irregularshaped of flakes and rough surfaces. This shape of powder was due to drying process using a double drum drier that break the granule of each excipient and turn it into irregular thin flakes form. However, the variation 
Surini, et al.: Glimepiride Solid Dispersion using The Coprocessed Excipients

of powder particle size was affected by the force and the length of particle size reduction process. Particle size affects the flow rate of an excipient. Flow rate will decrease with the decrease of particle size. ${ }^{14}$

The measurement of moisture content is used in this study for the moisture content influences the physical properties of a substance such as weight, density, viscosity, refractive index, and electrical conductivity in any form of powders. The measurement of the moisture content showed that coprocessed excipient 1:2:2 had the highest moisture content, which might be caused of the coprocessed excipient 1:2:2 contain higher amount of MD, as maltodextrin DE 18-20 is the most hygrosopic one.

The flow rate evaluation of PVP-MD-PEG powder was done by placing the powder in flowmeter funnel and the surface was evenly leveled without any pressure and the instrument was started. The result showed that the flow rate difference might be due to different concentrations of PVP, MD and PEG in each excipient. Maltodextrin hygroscopic properties caused the higher moisture content. Poor flow rate could also cause by particle size, since the flow rate will decrease as the particle size decrease. ${ }^{14}$

In this study, glimepiride was dissolved in $400 \mathrm{ml}$ methanol and coprocessed excipient was dissolved in $100 \mathrm{ml}$ aquadest. Both solution was mixed and sprayed using spray dryer. The inlet and outlet temperature were set to $100^{\circ} \mathrm{C}$ and $70^{\circ} \mathrm{C}$, respectively. This method produced vary yield value that were caused by masses that sticks on spry dryer machine resulting in the decrease of dry powder produced.

The first solid dispersion characterization in this study was physical appearance. Solid dispersion by spray drying produced a white and finer powder. The result showed that the finer powders were produced by solid dispersion drying process might be caused by the method used for drying is using spray-dryer which produced a finer due to its drying system that involves atomizing and spraying a solution or dispersion containing iron and carrier materials in a hot chamber, resulting in evaporation of the water to leave a powder. ${ }^{17}$ The smaller size in compared to pure glimepiride were caused by its reduction when glimepiride and the co-processed excipient were melted into one and dried with spray-drying. ${ }^{16}$ Morphology affects flow properties, glimepiride in solid dispersion had an ideal form to have good flow properties. ${ }^{18}$ Solid dispersion morphology was finer and more uniform due to the use of spray dryer. The dry powders after spray drying are physically and chemically stable with minimal amounts of residual solvent. This makes a lot of differences compared to other ways of drying.

The FTIR analysis was conducted on solid dispersion of glimepiridecoprocessed excipient and its physical mixture using $\mathrm{KBr}$ tablet. Although the IR Spectrum is not displayed, the result showed that the absence of chemical interaction means solid dispersion did not change overall functional group of glimepiride. ${ }^{19}$ This indicates that solid dispersion spectra were only the summation of glimepiride and co-processed excipient and reflected that there was no major interaction between glimepiride and the coprocessed excipient.

The result of thermal analysis using differential scanning calorimetry (DSC) which showed the decrease of crystalline phase in solid dispersion makes that it assumed to be a homogeneous solution and only low energy was needed to melt the crystals present. ${ }^{20}$ Based on diffractograms height, solid dispersion peaks were smaller than pure glimepiride with lower intensity too, which indicate a transformation from crystalline phase into amorphous phase. ${ }^{19}$

Dissolution examination was conducted to glimepiride and glimepiridecoprocessed excipients solid dispersion. The result showed that from the dissolution profile of solid dispersion from all formulas, it shows the evident that there is a remarkable improvement in the dissolution rates of solid dispersion than pure glimepiride. ${ }^{21}$

\section{CONCLUSION}

PVP-MD-PEG coprocess excipient 2:1:1 was selected as the best excipient compared to other formulations with flow rate of $4.33 \mathrm{~g} / \mathrm{sec}$, moisture content of $4.96 \%$, and acidity degree of 6.52 . The glimepiride solid dispersion which was produced with the PVP-MD-PEG coprocessed excipient 2:1:1 was the best GMP-SD with dissolution rate up to 4-fold compared to pure glimepiride at $120 \mathrm{~min}$.

\section{ACKNOWLEDGEMENT}

The authors gratefully acknowledge to Directorate of Research and Community Engagements of Universitas Indonesia for financial support.

\section{CONFLICT OF INTEREST}

The authors have no conflict of interest to declare.

\section{ABBREVIATIONS}

BCS: Biopharmaceutical Classification System; DE: Dextrose Equivalent GMP: Glimepiride; GMP-SD: Glimepiride Solid Dispersion; DSC: Differential Scanning Calorimetry; FT-IR: Fourier Transform Infrared; MD: Maltodextrin; PEG: Polyethylene glycol; PVP: Polyvinylpyrrolidone; SEM: Scanning Electron Microscope; UV-Vis: Ultraviolet-Visible

\section{SUMMARY}

In this study, the coprocessed excipients of polyvinylpyrrolidon (PVP), maltodextrin (MD) and polyethylene glycol (PEG) was prepared, then applied in production of the solid dispersion of glimepiride (GMP-SD) by spray drying method to increase the dissolution rate of glimepiride. GMP-SD with the PVP-MD-PEG coprocessed excipients has benefit to enhance dissolution rate of glimepiride

\section{REFERENCES}

1. Avachat A, Ahire V. Characterization and evaluation of spray dried coprocessed excipients and their application in solid dosage forms. Indian J Pharm Sci. 2007;69(1):85.

2. Bansai AK, Nachaegari SK. Co processed excipients for solid dosage forms. Pharm Tech. 2004;28(1):52-65

3. Bhavsar SS, Patel NM. Development of directly compressible coprocessed excipient for dispersible tablets using 32 full factorial design. Int J Pharm Pharm Sci. 2009;1(1):125-48.

4. Shargel L, Andrew BCYU. Applied biopharmaceutics and pharmacokinetics ( $3^{\text {rd }}$ ed). Connecticut: Appleton and Lange. 2005;1-3,51.

5. Amidon GL, Lennernäs H, Shah VP, Crison JR. A theoretical basis for a biopharmaceutic drug classification: The correlation of in vitro drug product dissolution and in vivo bioavailability. Pharm Res. 1995;12(3):413-20.

6. Martin A, Swarbrick J, Cammarata A. Physical pharmacy ( $2^{\text {nd }}$ ed). Philadelphia: Lea and Febiger. 1990:425-6.

7. Aulton M. "Dissolution and Solubility" in Pharmaceutics: The science of dosage form design. Edinburgh: Churchill Livingstone. 2002.

8. Chiou WL, Riegelman S. Pharmaceutical application of solid dispersion system. J Pharm Sci. 1970;60(9):1281-303.

9. Kennedy JF, Knill CJ, Taylor DW. Maltodextrin in: Kearsley MW, Dziedzic SZ (Ed). Handbook of starch hydrolisis products and their derivatives. London: Blackie Academy and Professional. 1995:65-81.

10. Vilar G, Tulla-Puche J, Albericio F. Polymers and drug delivery systems. Curr Drug Deliv. 2012;9(4):367-94.

11. Frick A, Möller H, Wirbitzki E. Biopharmaceutical characterization of oral immediate release drug products. In vitro/in vivo comparison of phenoxymethylpenicillin potassium, glimepiride and levofloxacin. Eur J Pharm Biopharm. 1998;46(3):305-11.

12. Afieroho O, Okorie O, Okonkwo T. An ultraviolet-spectrophotometric method for the determination of glimepiride in solid dosage forms. Diabetes Technol Ther. 2011;13(6):671-4

13. Biswal S, Sahoo J, Murthy PN, Giradkar RP, Avari JG. Enhancement of dissolution rate if gliclazide using solid dispersion with polyethylene glycol 6000. AAPS PharmSciTech. 2008;9(2):563-70.

14. Smallenbroek AJ, Bolhuis GK, Lerk CF. The effect of particle size of disintegrants 
on the disintegration of tablets. Pharm Weekbl Sci. 1981;3(1):1048-51.

15. Dixit M, Kini A, Kulkarni P. Enhancing Solubility and Dissolution of Celecoxib by Spray Drying using Pluronic F 127. Indian J Pharm Edu Res. 2011;45(4):348.

16. Sareen S, Matthew G, Joseph L. Improvement in solubility of poor water-soluble drugs by solid dispersion. International Journal of Pharmaceutical Investigation. 2012;2(1):12-17.

17. Huang Y, Dai W. Fundamental aspects of solid dispersion technology for poorly soluble drugs. Acta Pharm Sin B. 2014;4(1):18-25.

18. Sarrate R, Ramón J, Carrillo C, Fàbregas A, García-montoya E, Pérezlozano P, et al Modification of the morphology and particle size of pharmaceutical excipients by spray drying technique. Powder Technol. 2015;270:244-55.

19. Makar R, Latif R, Hosni E, El Gazayerly O. Optimization for glimepiride dissolution enhancement utilizing different carriers and techniques. J Pharm Invest. 2013;43(2):115-31.

20. Roni M, Islam M, Kibria G, Rony M, Rahman M, Jalil R. Effects of Poloxamer and HPMC on the Dissolution of ClonazepamPolyethylene Glycol Solid Dispersions and Tablets. Indian J Pharm Edu Res. 2011;45(2):141.

21. Mohanty S, Biswal S, Biswal S, Sahoo J, Mahapatra A, Murthy P. Enhancement of Dissolution Rate of Glimepiride using Solid Dispersions with Polyvinylpyrrolidone K 90. Indian J PharmEdu Res. 2010;44(1):71.

Article History: Submission Date : 29-11-2017 ; Revised Date : 28-01-2018; Acceptance Date : 12-03-2018.

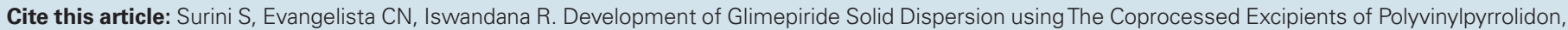

Maltodextrin, and Polyethylene Glycol. JYoung Pharm. 2018;10(2)Suppl:s45-s50. 